\title{
Investigations to Evaluate Gastric Mucoadhesion of an Organic Product to Ameliorate Gastritis
}

\author{
Christina Winter ${ }^{1}$, Sonja Hartl ${ }^{1}$, Dagmar Kolb ${ }^{2}$, Gerd Leitinger ${ }^{3}{ }^{(1)}$ and Eva Roblegg ${ }^{1,4, *}$ \\ 1 Institute of Pharmaceutical Sciences, Pharmaceutical Technology and Biopharmacy, University of Graz, \\ Universitätsplatz 1, 8010 Graz, Austria; christina.winter@uni-graz.at (C.W.); sonja.hartl@uni-graz.at (S.H.) \\ 2 Core Facility Ultrastructure Analysis, Center for Medical Research, Gottfried Schatz Research Center, \\ Medical University of Graz, Neue Stiftingtalstrasse 6/II, 8010 Graz, Austria; dagmar.kolb@medunigraz.at \\ 3 Division of Cell Biology, Histology and Embryology, Gottfried Schatz Research Center, Medical University of \\ Graz, Neue Stiftingtalstrasse 6/II, 8010 Graz, Austria; gerd.leitinger@medunigraz.at \\ 4 Research Center Pharmaceutical Engineering GmbH, Inffeldgasse 13, 8010 Graz, Austria \\ * Correspondence: eva.roblegg@uni-graz.at; Tel.: +43-316-380-8888
}

Received: 29 January 2020; Accepted: 3 April 2020; Published: 7 April 2020

\begin{abstract}
Gastritis is an inflammatory disease leading to abdominal pain, nausea, and diarrhea. While therapy depends on etiology, adhesive agents protecting the gastric tissue represent a promising treatment option. Caricol ${ }^{\circledR}$-Gastro is an organic product that significantly decreased gastritic abdominal pain in a recent clinical study. To investigate whether this beneficial effect can be attributed to the formation of a protective layer covering the gastric mucosa after oral application, several methods were used to determine adhesion. These include macro-rheological measurements and gastric mucin interactions, which were correlated to network formation, examined by Cryo-scanning electron microscopy technique, wettability via sessile drop method on human gastric adenocarcinoma cell layers, and ex vivo adhesion studies on gastric porcine tissue with the falling liquid film technique considering physiological conditions and Franz diffusion cells for quantification. The results showed that Caricol $^{\circledR}$-Gastro formed a stable viscoelastic network with shear thinning properties. It exhibited high wettability and spreadability and adhered to the excised gastric mucosa. We found that oat flour, as the main ingredient of $\mathrm{Caricol}^{\circledR}{ }^{\circledR}$-Gastro, supports the gel network regarding viscoelasticity and, to a lesser extent, adhesion in a concentration dependent manner. Moreover, our data highlight that a variety of coordinated methods are required to investigate gastric adhesion.
\end{abstract}

Keywords: mucoadhesion; organic product; rheology; wettability; falling liquid film technique; in vitro studies; ex vivo studies

\section{Introduction}

Gastritis is an inflammatory disease that affects the lining of the mucosa in the stomach. In principle, a distinction can be made between two forms of gastritis, i.e., acute and chronic gastritis. Acute gastritis occurs suddenly and can be caused by stress, medication intake (e.g., non-steroidal anti-inflammatory drugs or steroids), and alcohol or nicotine intoxication [1,2]. Due to damage to the mucosal defenses, surface necrosis takes place, which leads to symptoms, such as pain, loss of appetite, or nausea [3]. Chronic gastritis develops gradually over months and appears either as non-atrophic or atrophic form [4-7]. The atrophic form involves the loss of gastric glandular cells, which leads to a disorder in secretion of essential substances and consequently digestive problems [8]. It is mostly caused by infections, mainly by Helicobacter pylori, but can also have an autoimmune origin $[3,5]$. Other causes include infections by organisms, such as Mycobacterium avium intracellular, Herpes simplex, and Cytomegalovirus, bile acid reflux, radiation therapy and others. Thereby, symptoms include pain in the upper abdomen, bloating, nausea, vomiting, and diarrhea [8,9]. 
Treatment of gastritis depends on the etiology. Infectious chronic gastritis is treated with specific antibiotics combined with proton-pump inhibitors, and autoimmune gastritis is managed with iron and vitamin B 12 substitutes [10-12]. Other forms of alleviation of gastritis include cessation of stress, medications, alcohol and nicotine, and spicy food $[9,11,13]$. Additionally, cytoprotective and mucoprotective agents can be used that protect the injured lining mucosa in the stomach and support standard medical treatment $[1,12]$. Caricol ${ }^{\mathbb{R}}-$ Gastro is an organic product that has been recently investigated in a randomized, double blind placebo controlled clinical trial regarding its effect on patients diagnosed with chronic gastritis. The results showed that the pain load associated with chronic gastritis was significantly reduced in the patient group treated with Caricol ${ }^{\circledR}$-Gastro [14]. Caricol ${ }^{\circledR}$-Gastro is available as gel (packed into sticks) and consists mainly of two natural components, i.e., papaya pulp and oat flour. Papaya contains a variety of enzymes, such as papain, chymopapain, and lysozyme, Vitamin C, antioxidants, bioflavonoids, and minerals, which are responsible for a beneficial nutritive effect [14-17]. Clinical observations showed that in patients with gastrointestinal disease papaya interacted with reactive oxygen species and reduced the secretion of gastric acid caused by histamine $[17,18]$. Oat from Avena Sativa L. comprises fatty acids, antioxidants, vitamins (E and B), minerals, and cell wall polysaccharides such as starch and $\beta$-glucan. $[19,20]$. The cell wall polysaccharides consist of 9-28\% $\beta$-glucan and $40-60 \%$ starch, whereas the amylose and amylopectin content in oat starch is about $25 \%$ and $75 \%$, respectively [21,22]. Studies show that $\beta$-glucan fibers contribute most to the viscosity and wetting ability of oat preparations [22-24]. These fibers form a mucous gel upon contact with water that is supposed to adhere to the moist surface lining in the stomach and to act as a protective layer. The adhesion between two materials, at least one of which is a mucous membrane surface, is also called mucoadhesion. In the field of drug formulation, mucoadhesion is an important characteristic for prolonging the retention time of dosage forms on different mucous membranes, such as the gastrointestinal tract, vagina, lung, and oral mucosa. On the one hand, the absorption of drugs can be increased; thus, improving their bioavailability, and on the other hand, (injured) tissues can be moistened or protected. The process of mucoadhesion is divided into two stages, i.e., the contact and the consolidation stage [25]. The contact stage is defined as intimate contact (wetting) between the polymer and the mucous membrane, while the consolidation stage encompasses the various physicochemical interactions leading to prolonged adhesion [26,27]. There are six theories that govern the interactions and mechanisms of mucoadhesion, including (i) wetting, (ii) dehydration, (iii) diffusion, (iv) adsorption, (v) electronic, and (vi) mechanical theories [25,26,28-33]. Moreover, the extent of adhesion of a particular polymer depends on various factors such as molecular weight, flexibility of the polymeric chains, water retention capacity, viscoelastic behavior, and ionic state of the polymer. However, these properties are dependent on the physiological $\mathrm{pH}$ of the respective mucosal area and the polymer concentration and should, thus, be taken into account $[25,28,34]$. In vivo methods to determine mucoadhesion in the gastrointestinal tract are scarce and include e.g., gamma scintigraphy, the usage of radioisotopes/x-ray, or the tension resistance method [35-37]. However, these methods often show incoherence among the results due to different parameters and conditions. Moreover, in vivo studies are expensive, time-consuming, and require ethical approval [38]. As an alternative, in vitro examinations can be carried out to predict the behavior of a formulation under physiological conditions and to improve the understanding of underlying mechanisms of action. This would reduce costs incurred by clinical studies, enable a faster screening of dosage forms, and facilitate rational formulation design or-if necessary—formulation improvement [39,40]. However, for the characterization of mucoadhesive effects, there is no universally valid in vitro model available Therefore, it is hypothesized that a combination of coordinated methods has to be applied. The most frequently used in vitro methods include rheological techniques, surface plasmon resonance, isothermal titration calorimetry, tensile strength test, shear strength test, peel strength test, and contact angle measurements performed on specific surfaces [28,34,41]. In addition, mucoadhesion can be tested ex vivo using excised tissues [38,39,41,42]. Thereby, the everted gut sac technique, atomic 
force microscopy and the falling liquid film method are the most frequently used techniques to study mucoadhesion along the oro-gastrointestinal tract [43-45].

Since the efficacy of Caricol ${ }^{\circledR}$-Gastro to alleviate abdominal pain and reduce constipation and bloating has been proven in clinical studies, it is obvious that it forms a protective layer over the gastric mucosa due to its mucoadhesive properties $[14,16]$. Therefore, to be able to correlate clinical effectiveness with in vitro performance, a suitable mucoadhesion tool was built and $\mathrm{Caricol}^{\circledR}{ }_{-}$-Gastro was used as model substance. To this end, the viscoelastic behavior and the gel-like network formation of the agent was investigated taking into account physiological factors, such as the production of gastric juice, gastric motility, physiological body temperature $\left(37^{\circ} \mathrm{C}\right)$ and gastric mucin interaction [46]. In order to evaluate whether adhesive properties can be attributed to the oat flour only, additional investigations were carried out with pure oat flour formulations soaked and heated in water considering the influence of the polymer's concentration. Moreover, wettability studies were performed on human gastric adenocarcinoma (AGS) cell-coated surfaces considering horizontal and vertical $\left(35^{\circ}\right)$ positions to properly mimic physiological conditions in the stomach. Excised gastric porcine mucosa was used with the falling liquid film technique to macroscopically study the adhesion behavior of the organic product on physiologically relevant tissues [47]. In order to be able to carry out quantification, all formulations were stained with methylene blue and applied to cut pieces of excised gastric porcine mucosa. The mucosa was placed into agitated Franz diffusion cells to ensure controlled conditions during the experiment. Finally, the amount of stained formulation washed away over time was measured spectrophotometrically [48].

\section{Materials and Methods}

\subsection{Preparation of the Investigated Formulations}

The main ingredients of the studied formulation (i.e., commercially available Caricol ${ }^{\circledR}$-Gastro) are summarized in Table 1. The preparation of Caricol ${ }^{\circledR}$-Gastro is described in patent EP 3131565 A2. Briefly, oat flour is dispersed in water, heated to $70-90^{\circ} \mathrm{C}$, and stirred in a closed system for at least $30 \mathrm{~min}$. Subsequently, papaya pulp, natural flavoring, and apple concentrate, to adjust the $\mathrm{pH}$ to 4.5-5.5, are added, cooled and filled into sticks. The oat extracts used in this study were produced from oat flour powder as aqueous decocts, according to a modified procedure described in European Pharmacopoeia (Ph. Eur. 9.1.4.3, 23a). For this purpose, two extracts were prepared to study the influence of the concentration on the network formation taking into account the stirring time. First, $6.25 \mathrm{~g}(w / w)$ of the oat powder (according to recipe specification) were dispersed in MQ-water to $100 \mathrm{~g}$, heated to $100{ }^{\circ} \mathrm{C}$, stirred for 30 and $60 \mathrm{~min}$ at $250 \mathrm{rpm}$ in a closed vial, respectively, and cooled to room temperature (RT, referred to as oat I). Second, to consider the other semi-solid and liquid ingredients of Caricol ${ }^{\circledR}$-Gastro (i.e., papaya pulp, apple juice concentrate, and residual water), the oat powder concentration was adjusted accordingly to $14.29 \mathrm{~g}(w / w)$. Processing was carried out using the same method as described above (referred to as oat II).

Table 1. Overview of the ingredients of $\mathrm{Caricol}^{\circledR}$-Gastro.

\begin{tabular}{ccc}
\hline Caricol ${ }^{\circledR}$-Gastro & Ingredients & Concentration (g) \\
\hline & Papaya pulp (containing pectin, more specifically & \\
& $\alpha-(1 \rightarrow 4)$-D-galacturonan main polymeric component) ${ }^{*}$ & $39.44 / 100 \mathrm{~g}$ \\
$100 \mathrm{~g}$ aqueous gel & Oat flour (containing starch and $\beta$-glucan as main & $6.25 / 100 \mathrm{~g}$ \\
& polymeric component) & $10.5 / 100 \mathrm{~g}$ \\
& Apple juice concentrate & $0.08 / 100 \mathrm{~g}$ \\
& Natural flavoring & \\
\hline
\end{tabular}

* obtained from biological origin. 


\subsection{Macrorheological Measurements Taking into Account Interactions with Simulated Gastric Fluid and Gastric Mucins}

Rheological studies were conducted with Caricol ${ }^{\circledR}$-Gastro, oat I and oat II. To prevent liquid evaporation a built-in evaporation protection hood was used for all measurements. The linear viscoelastic region (LVE) was determined via frequency sweep between 0.1 and $100 \mathrm{~Hz}$ and amplitude sweep at a constant angular frequency of $0.1 \mathrm{rad} / \mathrm{s}$ and deformation $(\gamma)$ between 0.1 to 100 . The viscoelastic moduli G' (i.e., elastic modulus) and G" (i.e., viscous modulus) were determined via strain-controlled oscillation using a Physica MCR 301 rheometer (Anton Paar) with a CP-50-1 measurement system (cone-plate geometry) at RT $\left(25 \pm 0.5{ }^{\circ} \mathrm{C}\right)$ and $37 \pm 0.5{ }^{\circ} \mathrm{C}$ [42]. The loss factor $\tan \delta$, which describes the ratio of viscous and elastic behavior, was calculated according to $G^{\prime \prime} / G^{\prime}$ for each measurement point. Viscosity $\eta$ was determined using the same measurement system with shear rate-controlled rotation at both $25 \pm 0.5^{\circ} \mathrm{C}$ and $37 \pm 0.5^{\circ} \mathrm{C}$. The applied shear strain for both experiments were angular frequencies between 0.1 and $1001 /$ s to consider naturally occurring strain due to gastric motility [43].

To consider interactions with gastric fluid, Caricol ${ }^{\circledR}$-Gastro, oat I and oat II were mixed with simulated gastric fluid (SGF) in the ratio 1:1. SGF was prepared according to the United States Pharmacopoeia [49]. Briefly, $2.06 \mathrm{~g} \mathrm{NaCl}$ were dissolved in $1000 \mathrm{~g} \mathrm{MQ}$-water and the $\mathrm{pH}$ was adjusted to $\mathrm{pH}$ 1.2. The viscoelastic properties were determined at $37^{\circ} \mathrm{C}$ using the same test setup as the pure formulations. The results of both measurements were compared.

To investigate interactions between porcine stomach mucin and Caricol ${ }^{\circledR}$ _Gastro, oat I and oat II respectively, rheological studies were carried out. To this end, lyophilized mucin from porcine stomach (Sigma Aldrich, Munich, Germany, Type III, partially purified powder) was dispersed in $0.1 \mathrm{M} \mathrm{HCl}$ (10 mg/mL). [50,51]. Subsequently, the mucin solution was mixed with each formulation to a final mucin concentration of $5 \mathrm{mg} / \mathrm{mL}$ and adjusted. The viscoelastic properties were determined at $37^{\circ} \mathrm{C}$ with the same test setup as before and used to calculate interaction parameters according to Rossi et al. [46,52,53]. Briefly, the viscoelastic parameters were calculated as differential values to assess $\Delta \eta / \eta$, $\Delta G^{\prime} / G^{\prime}$ and $\Delta \tan \delta$ as summarized in Table 2. To consider shear strain, the value at the lowest angular frequency $\left(0.1 \mathrm{~s}^{-1}\right)$, referred to as low in the graph, medium angular frequency $\left(5.18 \mathrm{~s}^{-1}\right)$, referred to as medium in the graph, an highest angular frequency $\left(100 \mathrm{~s}^{-1}\right)$, referred to as high in the graph were considered for calculation.

Table 2. Overview of the calculations for viscoelastic parameters according to.

\begin{tabular}{|c|c|c|}
\hline $\begin{array}{l}\text { Interaction Parameters } \\
\text { (Differential) }\end{array}$ & Formula & Shear Rates \\
\hline$\Delta \eta / \eta$ & $\Delta \eta=\eta_{\text {mixture }} *\left(\eta_{\text {formulation }}+\eta_{\text {mucin }}\right)$ & \multirow{3}{*}{$\begin{array}{c}0.1 \mathrm{~s}^{-1} \text { (low), } 5.18 \mathrm{~s}^{-1} \text { (medium) } \\
100 \mathrm{~s}^{-1} \text { (high) }\end{array}$} \\
\hline$\Delta \mathrm{G}^{\prime} / \mathrm{G}^{\prime}$ & $\Delta \mathrm{G}^{\prime}=\mathrm{G}_{\text {mixture }}^{\prime}-\left(\mathrm{G}_{\text {formulation }}^{\prime}+\mathrm{G}_{\text {mucin }}\right)$ & \\
\hline$\Delta \tan \delta$ & $\Delta \tan \delta=\tan \delta_{\text {mixture }}-\left(\tan \delta_{\text {formulation }}+\tan \delta_{\text {mucin }}\right)$ & \\
\hline
\end{tabular}

\subsection{Cryo-Scanning Electron Microscopy (Cryo-SEM) Preparation}

To confirm the network formation evaluated from rheological studies, the microstructure of Caricol $^{\circledR}$-Gastro, oat I and oat II were visualized using the Cryo-SEM technique (Quorum PP3010T). Prior to visualization the samples were frozen under slush liquid nitrogen and transferred with a vacuum transfer device into the preparation chamber for subsequent processing and observation. The cryo-preparation chamber was connected to a GEMINI Sigma 500 (ZEISS Company, Oberkochen, Germany) SEM, which included a nitrogen gas cold stage. In the chamber the samples were fractured, sublimated, and sputter coated with palladium. The fractured material was transferred into the SEM specimen chamber before image recording. 


\subsection{Calculation of the Pore-Size Distribution}

The pore size distributions were calculated using ImageJ-Fiji software package. To this end, the SEM-images were converted into binary files using the threshold function. From the inverted binary files, the Feret diameters of at least 500 pores were calculated. For the determination of the pore-size, each pore was assumed as a particle and calculated according to Equation (1), where the pore is defined as the volume of a particle $(\mathrm{V})$ and $\mathrm{d}$ is the Feret diameter:

$$
V=\frac{4}{3} \times \pi \times\left(\frac{d}{2}\right)^{3}
$$

The pore-size distribution was then calculated as volume percentage to consider large and small pores.

\subsection{In Vitro Wettability Studies}

\subsubsection{AGS-Cell Cultivation}

Human gastric adenocarcinoma cells (AGS) were kindly provided by B. Rinner (Medical University Graz, Austria) and cultivated in high glucose Dulbecco's modified Eagle medium (DMEM) supplemented with $2 \mathrm{mM}$ L-Glutamine and 10\% fetal bovine serum (FBS) purchased from Gibco, Life Technology Corporation (Painsley, UK). Culture conditions were kept constant at $37{ }^{\circ} \mathrm{C}$ in a humid $95 \%$ air $/ 5 \% \mathrm{CO}_{2}$ atmosphere. Routinely, medium was changed every other day and AGS-cells were sub-cultivated at $80 \%$ confluence with $0.25 \%$ trypsin-EDTA at a split ratio of 1:6. Prior to use, cells were cultured on glass coverslips $\left(\varnothing 25 \mathrm{~mm}\right.$ ) at a concentration of $1.5 \times 10^{5}$ cells/slip. After careful microscopic verification of the formation of a confluent cell layer, cells were further treated for contact angle studies, according to previously published protocols [44-46]. Briefly, the cover slips were washed with phosphate buffered saline (PBS, pH 7.4, Gibco, Life Technologies Corporation, Painsley, UK) and fixed in a neutral buffered 10\% formalin solution for 15 min (Sigma-Aldrich ${ }^{\circledR}$, Munich, Germany). The cells were further dehydrated in an ascending alcohol (EtOH) series, i.e., $50 \%$, $70 \%, 96 \%$, and $100 \%$ alcohol (i.e., ethanol, EtOH, analytical grade, VWR, Vienna, Austria) series for $30 \mathrm{~s}$ each to minimize shrinkage effects resulting in inhomogeneous surfaces. To consider dilution of the formulation with gastric juice, Caricol ${ }^{\circledR}$-Gastro was mixed with $0.1 \mathrm{M} \mathrm{HCl}$ in the ratio $1: 1$ prior to the contact angle measurements.

\subsubsection{Contact Angle Measurements}

The prepared cell surfaces were utilized to determine wettability effects via contact angle measurements at the liquid/semisolid interface. Therefore, the glass slides with the fixed cells were placed horizontally and in a $35^{\circ}$ angle by gluing the slide on a metal piece $\left(60 \times 45 \mathrm{~mm}, 35^{\circ}\right.$ slope). Each measurement was carried out with the sessile drop method at $22^{\circ} \mathrm{C}$ with a drop volume of $1 \mu \mathrm{L}$. Images of the liquid droplets that settled on the cell layers were captured immediately after the drop wetted the surface. Contact angles were analyzed with the standard software using the Young equation (Equation (2))

$$
\gamma_{L G} \times \cos \theta=\gamma_{S G}-\gamma_{S L}
$$

where, $\gamma_{\mathrm{SL}}$, and $\gamma_{\mathrm{SG}}$ are the corresponding surface energies of liquid solid interface per unit area [54,55]. All investigations were carried out six times $(n=6)$. A MQ- $\mathrm{HCl}$ mixture (resulting in $0.05 \mathrm{M} \mathrm{HCl}$ ) was used as control. A schematic illustration of the wetting experiments is shown in Figure 1. 


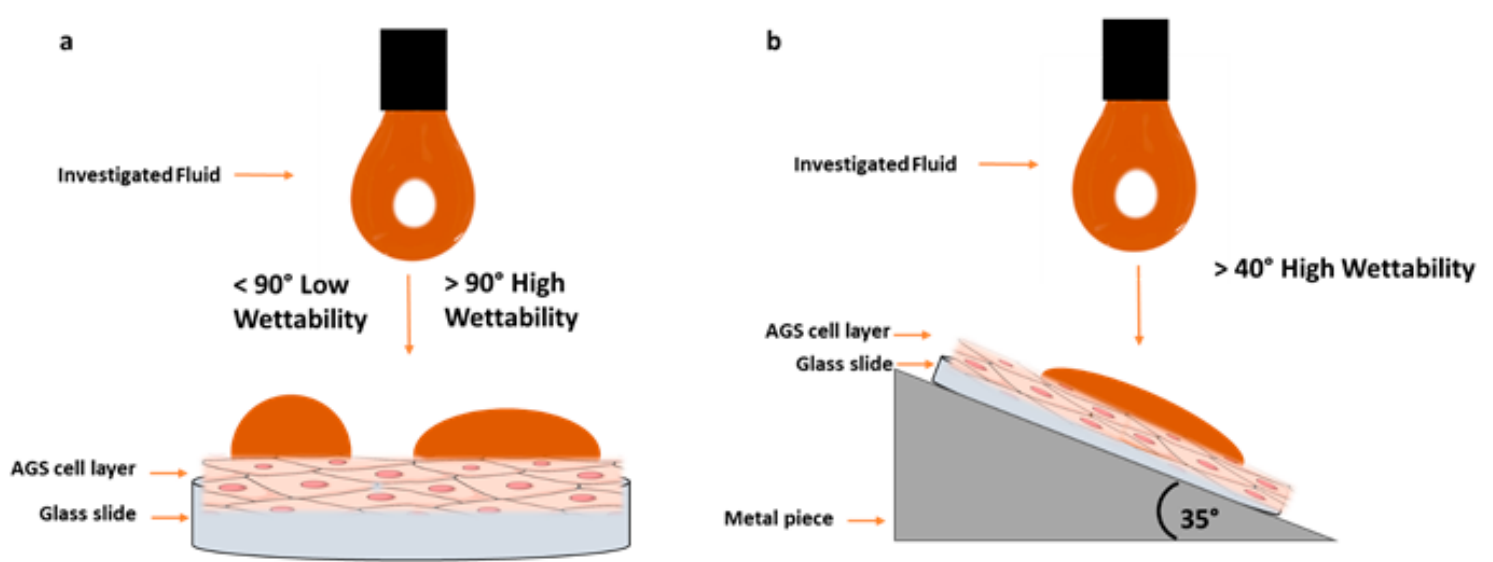

Figure 1. Schematic illustration of the experimental wettability set-up performed at horizontal (a) and $35^{\circ}$ (b) positions.

\subsection{Ex Vivo Studies with the Falling Lquid Film Technique}

Mucoadhesion of Caricol ${ }^{\circledR}$-Gastro was investigated using gastric porcine excised mucosa on a modified falling liquid film technique as previously described by Gradauer et al. [39]. For this, porcine stomach was obtained from freshly sacrificed pigs (age < 6 months; Marcher Fleischwerke, Graz, Austria) and transported in $4{ }^{\circ} \mathrm{C}$ Krebs buffer (Sigma-Aldrich ${ }^{\circledR}$, Munich, Germany) to the laboratory. The gastric mucosa was cut from the grater curvature into $20-30 \mathrm{~cm}^{2}$ pieces, carefully rinsed with Krebs buffer and mounted with the mucosal side up on a semicylindrical Plexiglas ${ }^{\circledR}$ tube at a $35^{\circ}$ angle. The equipment was put on a shaker, agitated at $100 \mathrm{rpm}$ to mimic gastric motility [47]. A peristaltic pump was used to constantly flush the mucosa with $0.1 \mathrm{M} \mathrm{HCl}$ (pump speed of $2 \mathrm{~mL} / \mathrm{min}$ ), simulating the gastric fluid in the stomach. For visualization purpose, $2 \mathrm{~g}$ of $\mathrm{Caricol}^{\circledR}$-Gastro were died with $5 \mathrm{mg}$ of methylene blue and directly applied on the top of the tube to mimic the transport through the esophagus and the gastric fold to the pyloric sphincter. The amount of remaining material was macroscopically investigated over a time period of $30 \mathrm{~min}$ and compared to $2 \mathrm{~g}$ organic oat I and oat II dyed with $5 \mathrm{mg}$ of methylene blue and $2 \mathrm{~g}$ MQ-water dyed with $5 \mathrm{mg}$ of methylene blue (control).

\section{Ex Vivo Quantification with Franz Diffusion Cells}

To quantify the amount adhering to the excised gastric tissue, $0.5 \mathrm{~g}$ of each formulation stained with methylene blue $(10 \mu \mathrm{L}$, concentration: $1 \mathrm{mg} / \mathrm{mL})$ was applied to adequate sections (approximately $2 \times 2 \mathrm{~cm}$ ) of the gastric porcine mucosa. MQ water dyed with methylene blue was used as control. The mucosa sections were placed into static Franz diffusion cells and each donor compartment was filled with $1 \mathrm{~mL}$ of $0.1 \mathrm{M} \mathrm{HCl}$. The whole equipment was placed in an incubator at $37^{\circ} \mathrm{C}$ and agitated at $50 \mathrm{rpm}$. After 1, 5, 20, 30, and 60 min samples were withdrawn from the donor compartment and refilled with fresh media. Subsequently, the samples were centrifuged at 14,000 rpm and the methylene blue concentration in the supernatant was determined spectrophotometrically using a nano-photometer (Implen, Munich, Germany) via single wavelength measurement at $665 \mathrm{~nm}$ [43].

\subsection{Statistical Analysis}

Depending on the respective method, three- and six-fold determinations were carried out. The results are presented as the mean values \pm standard deviation (SD). To evaluate statistical significance between Caricol ${ }^{\circledR}$-Gastro, oat I, oat II and control (MQ-water), one-way analysis of variance (ANOVA) was used. Differences were considered to be significant at a level of $p<0.05\left(^{*}\right), p<0.01\left(^{* *}\right.$, and $p<0.001{ }^{(* * *)}$. 


\section{Results}

\subsection{Macroscopical Evaluation of the Extracts}

After the 30 min of stirring and heating according to Ph. Eur. 9.1.4.3, 23a, no complete swelling of the oat powder could be achieved resulting in an inhomogeneous dispersion. After increasing the stirring time to $60 \mathrm{~min}$, a homogenous swollen dispersion was obtained.

\subsection{Rheological Analysis}

Prior to the oscillation measurements, the LVE region of each formulation was determined at $37^{\circ} \mathrm{C}$. Both amplitude and frequency sweep were carried out to ensure that the strain response of the formulations was proportional to the input strain amplitude. The results showed that the measurement range for deformation $(\gamma=1)$ and the frequency between 0.1 to $100 \mathrm{~Hz}$, which equals 6.28 to $628.31 \mathrm{rad} / \mathrm{s}$, were within the LVE region (Figure $2 \mathrm{a}, \mathrm{b}$ ). The viscoelastic characteristics for Caricol ${ }^{\circledR}$-Gastro showed that the elastic modulus was larger than the viscous modulus $\left(G^{\prime}>G^{\prime \prime}\right)$. This suggests the formation of a crosslinked network. This network remained stable over a wide range of shear rates $(0.1-100 \mathrm{rad} / \mathrm{s})$. The loss factor tan $\delta$ decreased slightly from 0.7 at low shear rates $(0.01-0.4 \mathrm{rad} / \mathrm{s})$ to 0.5 at higher shear rates $(>0.5 \mathrm{rad} / \mathrm{s})$, which classifies Caricol ${ }^{\circledR}-$ Gastro as a strongly crosslinked viscoelastic fluid. The formulation exhibited the behavior of a non-Newtonian, shear-thinning fluid. While the dynamic viscosity changed as a function of the applied shear stress, alterations of the temperature, i.e., from RT to body temperature, did not impact the flow behavior of Caricol ${ }^{\circledR}$ _Gastro (Figure 3a,b). Oat I with a concentration of $6.25 \mathrm{wt} \%$ and stirred for one hour at elevated temperature did not show the characteristics of a crosslinked fluid (Figure $3 \mathrm{c}$ ). Contrary to Caricol ${ }^{\circledR}$-Gastro it was found that the viscous modulus dominated the elastic one, which significantly increased the tan $\delta$ to values $>25$ ***. With increasing temperature, the elastic modulus increased and the $\tan \delta$ values decreased to $1.2-1.6^{* * *}$ (Figure 3d). However still the ratio of moduli did not change. The standard deviations of all measuring points were high, indicating an inhomogeneous mixture. By increasing the oat flour concentration to $14.29 \mathrm{wt} \%$, which represents the concentration under real conditions, the ratio of the viscoelastic moduli changed at RT and $37^{\circ} \mathrm{C}$ (Figure 3e,f). The elastic modulus was larger than the viscous one and the $\tan \delta$ value was $<1$. Oat II exhibited a shear-thinning behavior and displayed the characteristics of a crosslinked viscoelastic fluid $\left(G^{\prime}>G^{\prime \prime}\right)$, which was comparable to Caricol ${ }^{\circledR}$-Gastro. The loss factor tan $\delta$ remained in a constant low range (i.e., 0.3-0.2) over the applied shear stress.
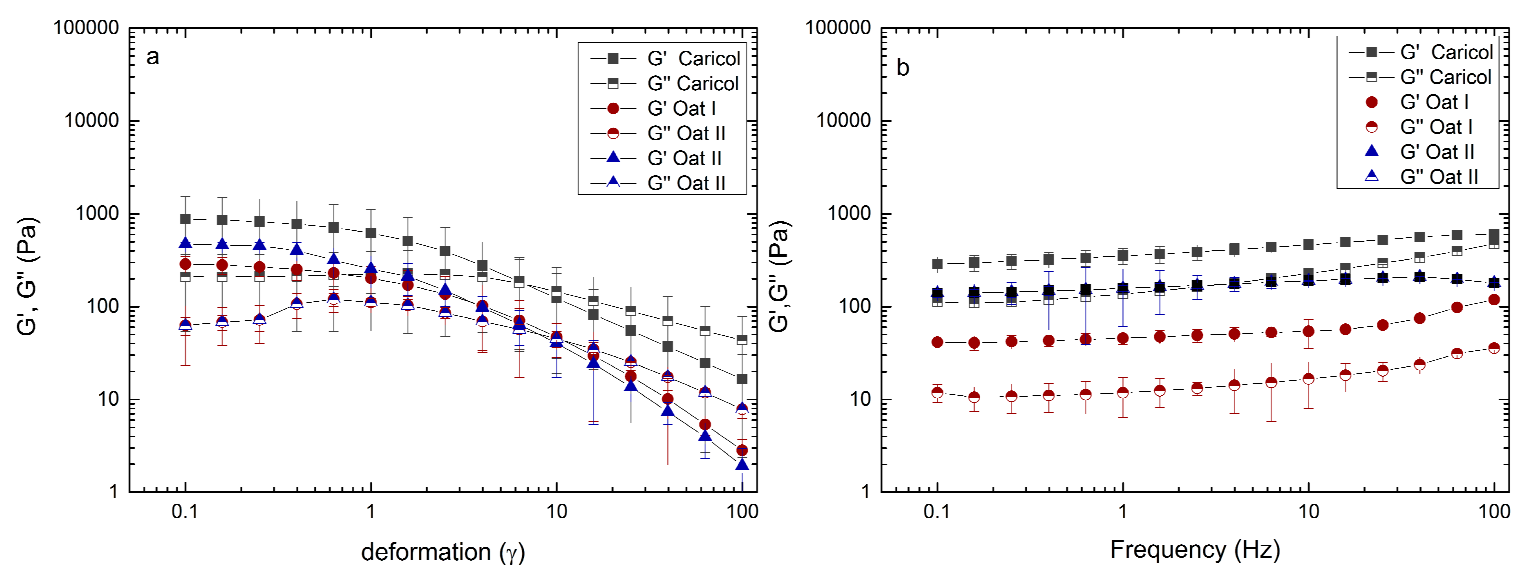

Figure 2. Determination of the linear viscoelastic region (LVE) determined via amplitude sweep (a) and frequency sweep $(\mathbf{b})$. 

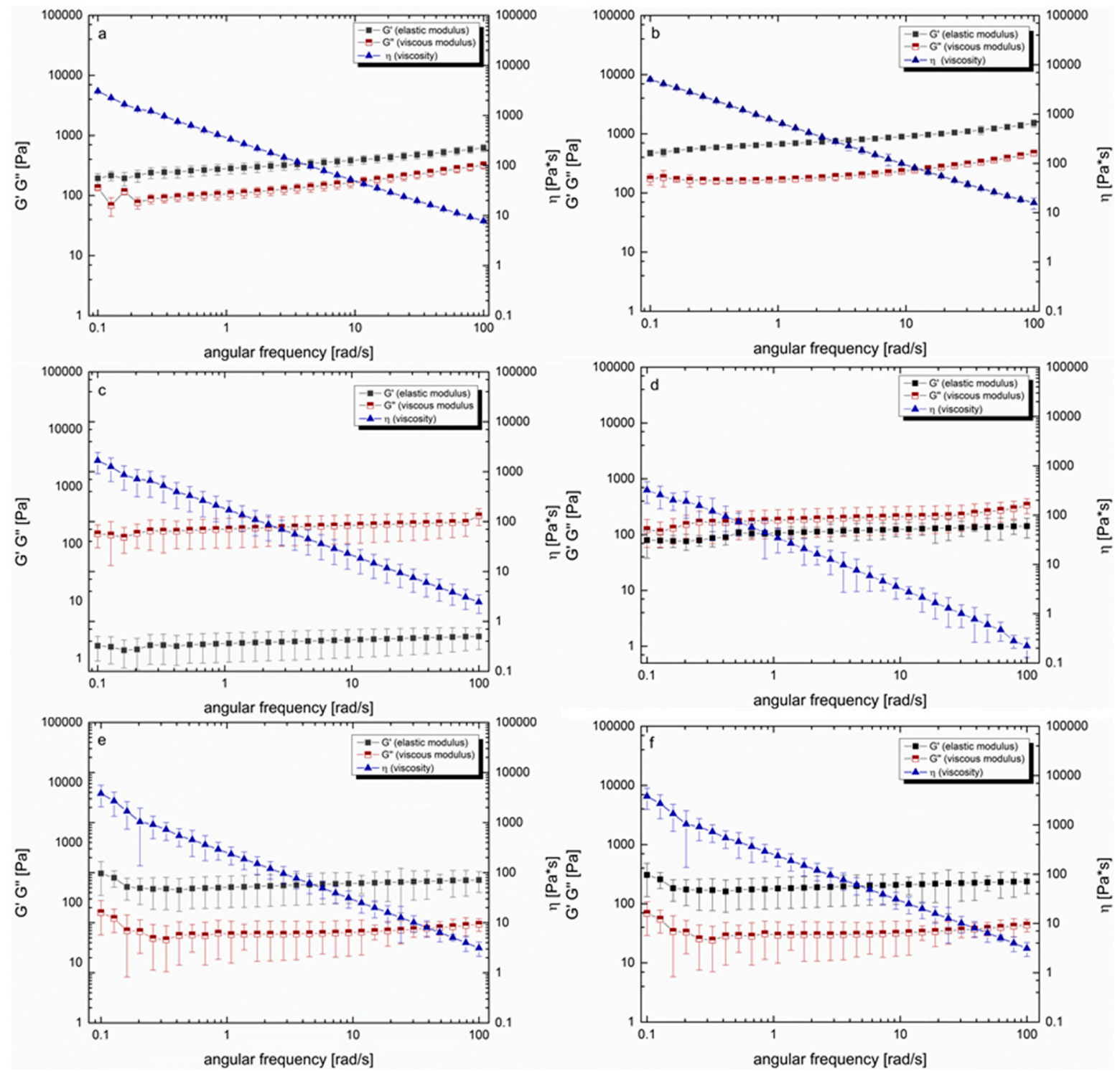

Figure 3. Rheological investigations of Caricol ${ }^{\circledR}$-Gastro at room temperature (RT) (a) and $37^{\circ} \mathrm{C}(\mathbf{b})$, oat I (6.25 wt \%) at RT (c) and $37^{\circ} \mathrm{C}(\mathbf{d})$, and oat II (14.29 wt \%) at RT (e) and $37^{\circ} \mathrm{C}(\mathbf{f})$.

After considering the residual gastric juice, it was found that due to the dilution step, the viscosity and viscoelastic moduli decreased in all three formulations. However, the moduli G' and G" remained in the same ratio as in the pure formulations (Figure $4 \mathrm{a}-\mathrm{c}$ ). Investigations regarding the mucin interactions showed that the elastic modulus dominated the viscous modulus over the entire shear rate. The loss factor tan $\delta$ remained nearly constant, i.e., 0.71 and 0.84 (data not shown). The viscosity, measured at $37^{\circ} \mathrm{C}$, ranged from $124 \mathrm{~Pa} \cdot \mathrm{s}$ at low shear rates to $0.1 \mathrm{~Pa} \cdot \mathrm{s}$ at the highest shear rate applied, exhibiting a shear thinning behavior. The addition of mucin to the formulations slightly increased the viscosity; however, the ratio of the viscoelastic moduli remained unchanged. 

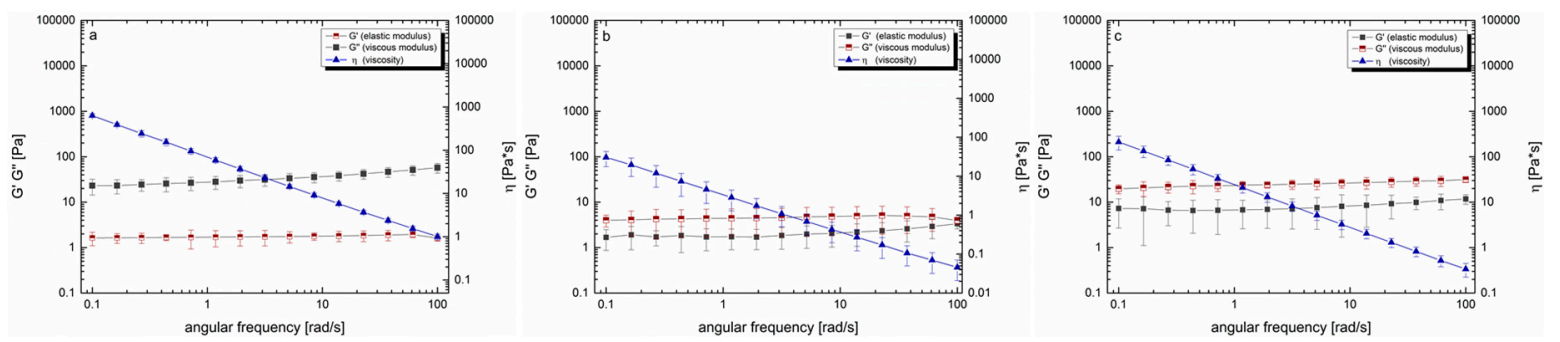

Figure 4. Rheological investigations of $\mathrm{Caricol}^{\circledR}{ }_{-}$-Gastro with simulated gastric fluid (SGF) (a), oat I with SGF (b), oat II with SGF (c) at $37^{\circ} \mathrm{C}$.

The differential parameters of the viscosity, elastic moduli and $\tan \delta$ were calculated by subtracting the sum obtained from the polymer solution and mucin solution from the value observed for the polymer-mucin mixture (Figure $5 \mathrm{a}-\mathrm{c}$ ). According to the literature, values higher than zero indicate the formation of mucoadhesive joints between the mucus solution and the polymer formulation [46]. In this study, the highest positive value was observed for Caricol ${ }^{\circledR}$-Gastro at low shear rates, indicating a mucoadhesive interaction. With increasing shear rates, the values decreased towards zero, which shows that the interactions became weaker with increasing shear strain. For oat I, we observed negative values at all three shear rates used for calculations. At higher shear rates, the values decreased even further, indicating that no adhesive interaction between mucin and oat was established. Oat II, which had a higher concentration, showed positive values for the viscosity at low and medium shear rates. The values calculated for the elastic moduli were only slightly positive, and again, the interactions became weaker with increasing shear strain until they were close to zero.
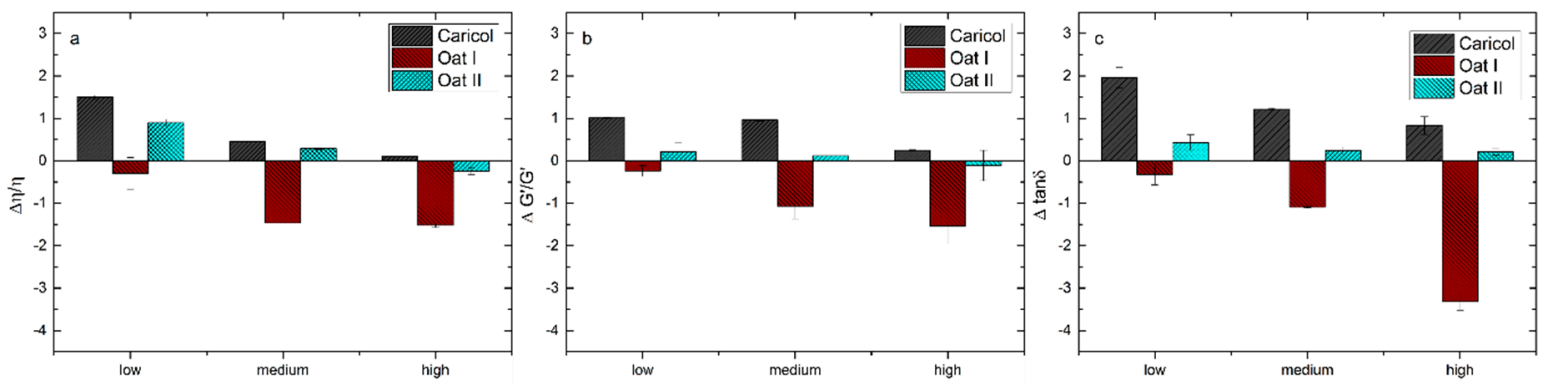

Figure 5. Rheological parameters for $\Delta \eta / \eta(\mathbf{a}), \Delta \mathrm{G}^{\prime} / \mathrm{G}^{\prime}(\mathbf{b}), \Delta \tan \delta(\mathbf{c})$ for Caricol ${ }^{\circledR}$-Gastro, oat $\mathrm{I}$, oat II in the presence of porcine gastric mucin calculated as differential interaction parameters [46].

\subsection{Microstructure and Pore Size Distribution}

Cryo-SEM images revealed a stable and coherent network structure for Caricol ${ }^{\circledR}$-Gastro with heterogeneous pore sizes. The pore size distribution ranged from 50 to $3200 \mathrm{~nm}$, with the highest volume percentage at 900 and $2700 \mathrm{~nm}$ (Figure 6a,d). Oat I also showed a network-like structure interspersed with starch particles, which exhibited sizes from 5 up to $60 \mu \mathrm{m}$. However, the pores were much larger displaying their highest volume percentage at $5800 \mathrm{~nm}$. Furthermore, the fibers appeared thinner and consequently more delicate compared to Caricol ${ }^{\circledR}$-Gastro (Figure 6b,e), which exhibited thick and tight network fibers. For oat II we observed more homogeneously dispersed starch particles and a tighter network structure. Below the range of $2000 \mathrm{~nm}$ a higher volume percentage of pores was observed compared to oat I (almost no pores). The volume percentage of pores larger than $5000 \mathrm{~nm}$ decreased compared to oat I and the maximum volume percentage was between 3600 and $4800 \mathrm{~nm}$ (Figure 6c,f). 

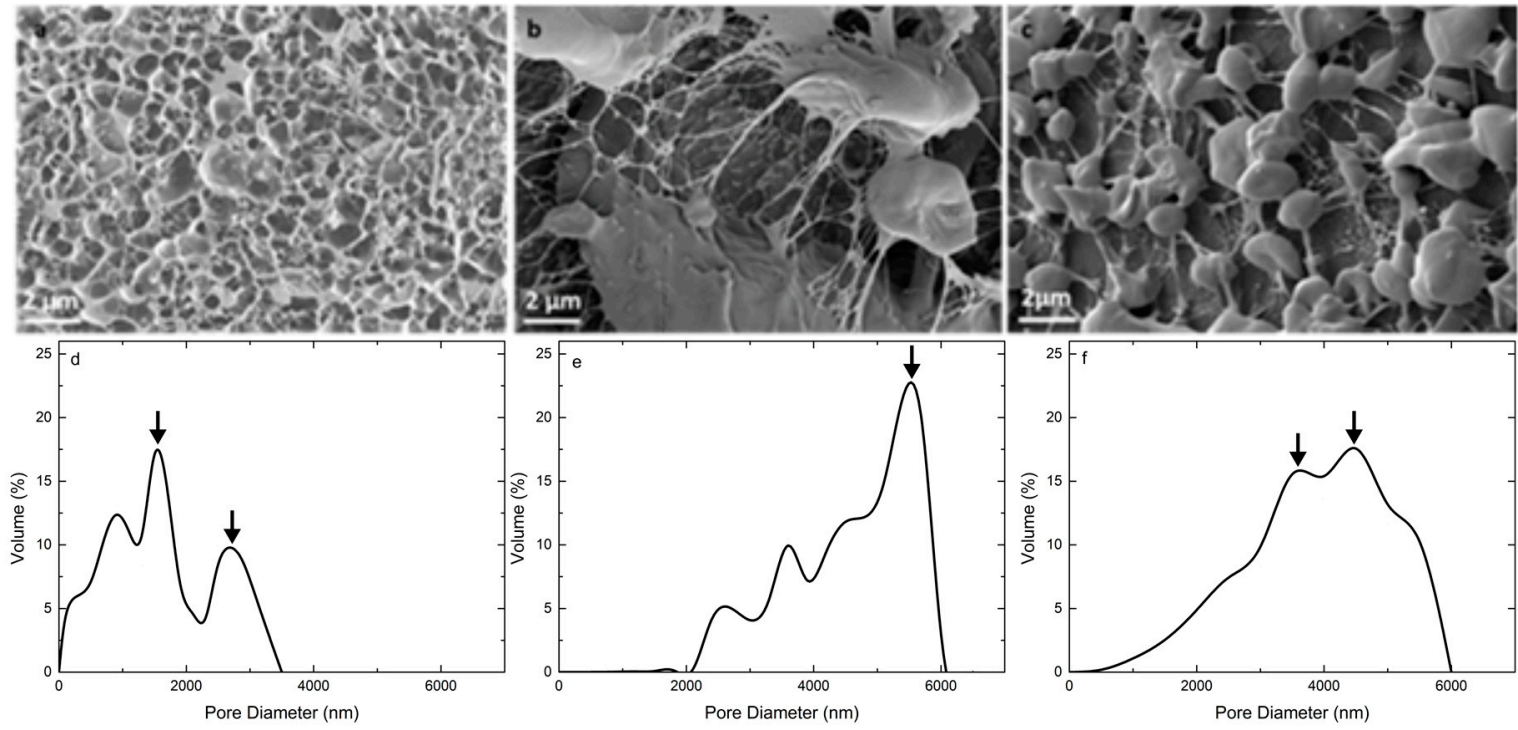

Figure 6. Representative Cryo-SEM micrographs of Caricol ${ }^{\circledR}$-Gastro (a), oat I (b) and oat II (c). The diagrams show the pore size distribution of Caricol ${ }^{\circledR}$-Gastro (c), oat I (d) and oat II (f).

\subsection{In Vitro Wettability Studies}

The contact angles for Caricol ${ }^{\circledR}$-Gastro were determined after mixing of the sample with $0.1 \mathrm{M}$ $\mathrm{HCl}$ to consider gastric juice in the stomach. On the horizontally arranged cell layer a contact angle of $38.4^{\circ} \pm 4.5^{\circ}$ was observed. Due to $35^{\circ}$ inclination of the cell layer, the values decreased to $28.0^{\circ}$ $\pm 0.8^{\circ}(p<0.01)$. For control, MQ- water was mixed with $\mathrm{HCl}$. The contact angle on AGS-cells was $101.1 \pm 2.0$ in the horizontal mode and decreased significantly $(p<0.001)$ in inclined position. Due to agglutination in the syringe it was not possible to determine the contact angle for oat I and II. All values are summarized in Table 3.

Table 3. Overview of contact angles obtained in horizontal and inclined position on adenocarcinoma (AGS)-cell layer surfaces.

\begin{tabular}{ccc}
\hline Formulation & Contact Angle Horizontal & Contact Angle Inclined $\left(35{ }^{\circ} \mathbf{C}\right)$ \\
\hline $\begin{array}{c}\text { Caricol }{ }^{\circledR} \text {-Gastro mixed with } \\
0.1 \mathrm{M} \mathrm{HCl}(1: 1)\end{array}$ & $38^{\circ} \pm 5^{\circ}$ & $28^{\circ} \pm 1^{\circ * *}$ \\
\hline Oat I, II & $\begin{array}{c}\text { Measurement not possible due to agglutination in the syringe and, } \\
\text { consequently, no drop formation possible. }\end{array}$ \\
\hline $\begin{array}{c}\text { MQ-water mixed with } 0.1 \mathrm{M} \\
\mathrm{HCl}(1: 1)\end{array}$ & $101^{\circ} \pm 2^{\circ}$ & $70^{\circ} \pm 2^{\circ * * *}$ \\
\hline
\end{tabular}

\subsection{Ex Vivo Falling Liquid Studies}

Ex vivo adhesion studies of Caricol ${ }^{\circledR}$-Gastro, oat I, oat II and MQ-water were carried out on excised porcine stomach mucosa using the falling liquid film apparatus. To this end, all formulations were stained with methylene blue in order to perform a precise macroscopic evaluation of the adhesion effect. The results showed that for Caricol ${ }^{\circledR}$-Gastro most of the initially applied material remained on the mucosa for more than $30 \mathrm{~min}$. Neither the rinsing with $\mathrm{HCl}$ during the experiments, to simulate the production of gastric acid, nor the motility mimicked by agitation influenced the layer formation. For oat II similar results were obtained. After $30 \mathrm{~min}$ oat II was partly washed away; most of the material was still found in the gastric folds. However, for oat I and MQ-water most of the initially 
applied material (i.e., $2 \mathrm{~g}$ each) was flushed away within the first $10 \mathrm{~min}$. For oat I and MQ-water only a thin blue-dyed layer remained.

\section{Ex Vivo Quantification via Franz Diffusion Cells}

Investigations to quantify the adhesive portion of the respective formulations tested showed that only small amounts of the formulation were washed away with Caricol ${ }^{\circledR}$-Gastro. There was hardly any increase in methylene blue, which suggests that most of the methylene blue contained in the formulation remained on the mucosa for a period of $60 \mathrm{~min}$ (Figure 7). This good adhesion behavior correlates with the investigations with the falling liquid technique. Furthermore, the results showed that oat II was washed away more slowly than oat I. However, in both formulations, significantly $(p<0.01)$ less methylene blue was washed away compared to the control. For MQ-water, which served as control, most of the methylene blue was washed off the surface within the first minute after application.

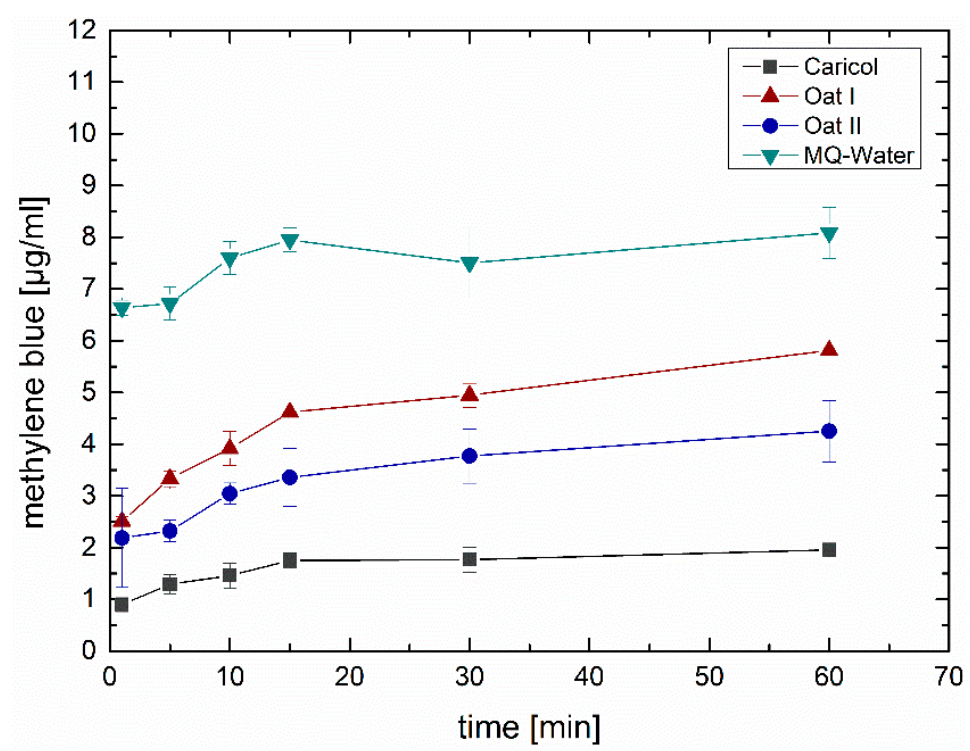

Figure 7. Quantification of methylene blue contained in the formulations (Caricol ${ }^{\circledR}$-Gastro, oat I, oat II and MQ-water) that was washed away from the porcine gastric mucosa over time.

\section{Discussion}

From recently performed clinical studies it is obvious that Caricol ${ }^{\circledR}$-Gastro shows adhesive properties to the gastric mucosa due to its pain-reliving effects in the clinical course of chronic gastritis [14]. To be able to build up a sound understanding of the mechanisms behind adhesive effects in a cost-effective and time-saving manner, related in vitro mucoadhesive test methods that take into account the physiological conditions of the respective barrier are highly important. Moreover, the establishment of such a tool would also allow to predict performances of other mucoadhesive dosage forms and facilitate rational formulation design. Thus, a combination of different methods, i.e., rheological methods, visualization of the network by SEM, in vitro wettability studies using the sessile drop method, and ex vivo studies conducted with the falling liquid film method were used and adjusted where necessary to investigate the mechanisms of adhesion of the model formulation Caricol ${ }^{\circledR}$-Gastro. Quantification of the material that was washed off the gastric mucosa was performed with Franz diffusion cells using methylene blue as staining agent. To examine whether the adhesive effects were mainly due to oat flour, we investigated pure oat preparations at different concentrations.

According to literature, the most valid rheological method to predict the deformation and flow behavior of substances and allows to draw conclusions on the adhesive properties, is to determine the viscoelastic characteristics via oscillatory measurements [43]. Thereby, viscoelastic materials are 
characterized by a delayed reaction to physiological occurring shear strain and relaxation. This behavior can depend on the degree of shear stress, shear time and temperature available at the respective biological site of interest $[43,48,49]$. To simulate physiological conditions in the stomach, we applied increasing steady shear stress up to $100 \mathrm{rad} / \mathrm{s}$ at $37^{\circ} \mathrm{C}$ adapted from Feng et al., who recently investigated the in vitro digestion process of oat products [50]. For Caricol ${ }^{\circledR}$-Gastro, it was found that the dynamic viscosity decreased dependent on the applied shear stress, indicating a shear thinning behavior. On the one hand, the temperature (i.e., $25^{\circ} \mathrm{C}$ versus $37^{\circ} \mathrm{C}$ ) did not impact the flow behavior of Caricol ${ }^{\circledR}$-Gastro. This is of paramount importance as it ensures that the gel does not liquefy in the body. However, on the other hand the shear-thinning properties are necessary for Caricol ${ }^{\circledR}$-Gastro to enter the stomach after oral application $[16,24,46]$. The viscoelastic properties of the product revealed a coherent and stable network under physiological shear stress as the elastic modulus dominated the viscous one [48,51]. Thereby, disulfide bridges were formed between the cysteine-rich domains and the $\beta$-glycans, which created a cross-linked three-dimensional gel, that was further strengthened by hydrogen bonds [56]. These results were further confirmed by Cryo-SEM. The micrographs of Caricol ${ }^{\circledR}$-Gastro showed a tight and coherent network with a maximum pore size diameter of $3200 \mathrm{~nm}$. This suggests that, considering the aforementioned shear thinning properties, Caricol ${ }^{\circledR}$-Gastro is able to spread evenly over the mucous membrane and coat it. Mixing with SGF did not change the viscoelastic moduli and shear thinning behavior, but only shifted the data towards lower values, thus, dilution with gastric juice can be neglected. The in vitro wettability studies correlated with the obtained data and showed that Caricol ${ }^{\circledR}$-Gastro resulted in a low contact angle, indicating high spreadability and consequently high wettability [45]. According to literature, contact angles below $90^{\circ}$ show increased spreadability of an investigated material on specific surfaces $[34,44,54]$. The contact angle for Caricol ${ }^{\circledR}$-Gastro decreased significantly $(p<0.01)$ from horizontal to inclined position $\left(38^{\circ} \pm 5^{\circ}\right.$ vs. $\left.28^{\circ} \pm 1^{\circ * *}\right)[37,44,45]$. The dilution to account for residual gastric juice did not affect the high wettability of Caricol ${ }^{\circledR}$-Gastro [55]. Contact angles for the pure (undiluted) Caricol ${ }^{\circledR}$-Gastro formulation were in the same low range (data not shown). The adhesive interactions with gastric mucus were strongest for Caricol ${ }^{\circledR}$-Gastro, which is consistent with the results from the rheological studies and the visualized network structure. The contact between the polymeric compounds of Caricol ${ }^{\circledR}$-Gastro, or more precisely $\beta$-glycan and $\alpha-(1 \rightarrow 4)$-D-galacturonan of pectin and the mucins led to physical entanglement [57,58]. Subsequently, chemical bonds, such as hydrogen bonds or ionic interactions between the mucins and the polymeric compounds were formed. These interactions decreased with increasing shear stress, which is consistent with the literature concerning other polymeric compounds [46-48]. This assumption was confirmed by the ex vivo experiments. To this purpose, excised gastric pig mucosa was used because of its similarity to human gastric tissue in terms of, e.g., histological and physiological features [56]. For an accurate macroscopic evaluation, all formulations tested were labeled with methylene blue $[55,57]$. For comparison purpose, the $35^{\circ}$ angle used for the contact angle measurements was also chosen for the falling liquid film apparatus. Moreover, gastric fluid production was considered by flushing the tissue with $\mathrm{HCl}$ and gastric motility was taken into account by shaking the apparatus at $50 \mathrm{rpm}$ during the entire experiment [47]. The results showed that Caricol ${ }^{\circledR}$-Gastro adhered effectively to the gastric mucosa supporting the in vivo data [14]. After $30 \mathrm{~min}$, most of the applied formulation was still in place, which can be attributed to the viscoelastic properties, the stable network formation and the good wettability of the formulation. More precisely, the first phase of mucoadhesion was initiated by chain interdiffusion, which was caused by hydrogen bonds and electrostatic interactions between the polymers and the residual mucoglycoproteins $[28,58]$. Thereby, the gastric mucoglycoproteins, mainly MUC5AC and MUC6, consist of side chains, i.e., $\mathrm{N}$-acetylgalactosamine, $\mathrm{N}$-acetylglucosamine, galactose, fucose and sialic acid, which interacted with the polymeric fibers in Caricol ${ }^{\circledR}$-Gastro. These include $\beta$-glucan from oat flour and $\alpha-(1 \rightarrow 4)$-D-galacturonan from papaya pulp $[14,59,60]$. The visual observation was confirmed by spectroscopic quantification. Therefore, it can be concluded that the formulation remains on the gastric mucosa long enough to protect the tissue and at the same time to allow the enzymes, i.e., papain and leukopapain, to interact with the ulcerated parts. Leukopapain in 
particular has been shown in both animal models and clinical settings to promote wound healing on contact with score tissue [16,59]. As a result, a reduction in pain and other gastritis-related symptoms, such as flatulence and constipation, is achieved [14,16].

Organic oat flour at low concentration (oat I) exhibited a different behavior since the viscous modulus was larger than the elastic one over the entire shear range, resulting in a high $\tan \delta$ value. This indicates that no stable network was formed. The micrographs also showed a delicate network structure interspersed with starch particles with comparatively large pores (highest pore volume percentage $5800 \mathrm{~nm}$ ). Hence, the network was less stable than Caricol ${ }^{\circledR}$-Gastro and was destroyed by shear stress applied during the rheological measurements. Moreover, the high standard deviations obtained during the measurements can be attributed most likely to the starch particles $[52,53]$. For oat I the in vitro contact measurements could not be conducted as agglutination of the syringe occurred, which was also because of the starch particles. The ex vivo results are in accordance with the mucin interaction studies carried out via rheological analysis. Oat I was washed away within the first few minutes because of the weakly structured network lacking chain interdiffusion and consequently mucin interaction.

At an increased oat flour concentration (oat II), the ratio of the viscoelastic moduli shifted, more specifically, the elastic modulus was larger than the viscous modulus resulting in an increased network stability. The network became tighter and the pore size distribution shifted towards smaller values (highest volume parentage: $3600-4800 \mathrm{~nm}$ ). However, the observed network still seemed less stable than that of $\mathrm{Caricol}^{\circledR}{ }^{\mathbb{}}$-Gastro. When mixed with SGF the network did not change. The adhesive studies showed that a higher adhesion to mucins was observed than for oat I, but the interactions were significantly $(p<0.01)$ weaker than in Caricol ${ }^{\circledR}$-Gastro. Again, spreadability could not be confirmed in vitro because of agglutination of the syringe. The ex vivo studies showed that due to the stable viscoelastic network comparable results to Caricol ${ }^{\circledR}$-Gastro were obtained after $10 \mathrm{~min}$. However, after $30 \mathrm{~min}$ the network loosened and adhesion decreased.

Our results show that the mucoadhesive behavior of $\mathrm{Caricol}^{\circledR}{ }_{-}-\mathrm{Gastro}$ is not only due to starch ( $\beta$-glycan) in oat, but also to the fact that other components, especially $\alpha$-( $1 \rightarrow 4)$-D-galacturonan from papaya pulp, contribute to the strengthening of the network. Consequently $\alpha-(1 \rightarrow 4)$-D-galacturonan increases the binding sites to the underlying tissue resulting in increased wettability and adhesion [60]. Adhesive interactions are usually triggered by hydrogen bonds as well as electrostatic and hydrophobic forces. Studies on pectin, with $\alpha-(1 \rightarrow 4)$-D-galacturonan as main polymer compound, show that the fibers have excellent wetting abilities and can both mix and interpenetrate with mucin chains [58]. According to literature most of the pectin in papaya consists of a smooth backbone structured by homogalacturonan regions [61]. The increased adhesion of Caricol ${ }^{\mathbb{}}-$ Gastro due to its polymeric compounds, i.e., $\beta$-glycan of oat and $\alpha-(1 \rightarrow 4)$-D-galacturonan of pectin, was clearly shown in the results of the mucin interaction studies and ex vivo investigations. While the network formation and interactions for $\beta$-glycan in oat can be increased via polymeric concentration, the mucin interaction of the individual compounds is comparatively weak $[57,58,62]$.

\section{Conclusions}

The data obtained make it clear that studies on mucoadhesion require a number of methods that need to be coordinated in order to obtain meaningful data. By performing rheological investigations, visualization of the network via cryo-SEM, rheological studies regarding mucin interactions, in vitro wettability, and ex vivo adhesion studies, considering quantification of the material that remains on excised gastric mucosa, a sound understanding of how Caricol ${ }^{\circledR}$-Gastro behaves in the stomach could be established. Caricol ${ }^{\circledR}$-Gastro forms a coherent and stable viscoelastic gel. It exhibits shear thinning properties, spreads on the gastric epithelium, and adheres to the gastric mucus for a certain period of time independent of residual dilution with gastric acid and the motility of the stomach. Thereby, a sufficient high concentration of organic oat rather supports the network formation and only to a lesser extent the adhesion. It is suggested that components of papaya pulp, such as $\alpha-(1 \rightarrow 4)$-D-galacturonan 
further strengthen the network, increase interactions with mucins and interpenetration with the mucin chains, resulting in prolonged residence time. The in vitro results correlate with the in vivo clinical data. This shows that the coordinated in vitro test combination can be used in the future to investigate mucosal adhesion of dosage forms and also allows a deeper understanding of the adhesive mechanisms in a cost-effective and time-saving manner. By exchanging the excised tissue for another epithelium (e.g., oral mucosa) and adjusting the physiological conditions (e.g., agitation or physiological fluid) one would have a variable system to perform mucoadhesion studies.

Author Contributions: Conceptualization, C.W. and E.R.; Methodology, C.W., S.H., D.K.; Validation, C.W., G.L. and E.R.; Formal Analysis, C.W.; Investigation, C.W., S.H., D.K.; Resources, D.K., G.L., E.R.; Data Curation, C.W., G.L., E.R.; Writing-Original Draft Preparation, C.W., E.R..; Writing-Review \& Editing, C.W., S.H., D.K., G.L., E.R.; Visualization, C.W., D.K., G.L.; Supervision, E.R.; Project Administration, E.R. All authors have read and agreed to the published version of the manuscript.

Funding: This research received no external funding.

Acknowledgments: The authors acknowledge the Open Access Funding by the University of Graz.

Conflicts of Interest: The authors declare no conflict of interest.

\section{References}

1. Azer, S.A. Gastritis. In StatPe; StatPearls Publishing: Treasure Island, FL, USA, 2019.

2. Vieth, M.; Neumann, H.; Falkeis, C. The diagnosis of gastritis. Diagnostic Histopathol. 2014, 20, $213-221$. [CrossRef]

3. Watari, J.; Chen, N.; Amenta, P.S.; Fukui, H.; Oshima, T.; Tomita, T.; Miwa, H.; Lim, K.J.; Das, K.M. Helicobacter pylori associated chronic gastritis, clinical syndromes, precancerous lesions, and pathogenesis of gastric cancer development. World J. Gastroenterol. 2014, 20, 5461-5473. [CrossRef] [PubMed]

4. Varbanova, M.; Frauenschläger, K.; Malfertheiner, P. Chronic gastritis-An update. Best Pract. Res. Clin. Gastroenterol. 2014, 28, 1031-1042. [CrossRef] [PubMed]

5. Massironi, S.; Zilli, A.; Elvevi, A.; Invernizzi, P. The changing face of chronic autoimmune atrophic gastritis: An updated comprehensive perspective. Autoimmun. Rev. 2019, 18, 215-222. [CrossRef]

6. Toh, B.H. Diagnosis and classification of autoimmune gastritis. Autoimmun. Rev. 2014, 13, 459-462. [CrossRef]

7. Waters, K.M.; Voltaggio, L. Gastritis: A pattern-based approach. Diagnostic Histopathol. 2017, 23, 513-520. [CrossRef]

8. Assarzadegan, N.; Montgomery, E. Gastric polyps. Diagnostic Histopathol. 2017, 23, 521-529. [CrossRef]

9. Cheung, L.Y. Pathogenesis, prophylaxis, and treatment of stress gastritis. Am. J. Surg. 1988, 156, 437-440. [CrossRef]

10. Wang, H.; Li, L.; Qin, L.L.; Song, Y.; Vidal-Alaball, J.; Liu, T.H. Oral vitamin B12 versus intramuscular vitamin B12 for vitamin B12 deficiency. Cochrane Database Syst. Rev. 2018, 90412039. [CrossRef]

11. Talebi Bezmin Abadi, A.; Yamaoka, Y. Helicobacter pylori therapy and clinical perspective. J. Glob. Antimicrob. Resist 2018, 14, 111-117. [CrossRef] [PubMed]

12. Asaka, M.; Kato, M.; Sakamoto, N. Roadmap to eliminate gastric cancer with Helicobacter pylori eradication and consecutive surveillance in Japan. J. Gastroenterol. 2014, 49, 1-8. [CrossRef] [PubMed]

13. Durham, R.M.; Shapiro, M.J. Stress gastritis revisited. Surg. Clin. N. Am. 1991, 71, 791-810. [CrossRef]

14. Weiser, F.A.; Fangl, M.; Mosgoeller, W. Supplementation of Caricol ${ }^{\circledR}$-Gastro reduces chronic gastritis disease associated pain. Neuroendocrinol. Lett. 2018, 39, 19-25. [PubMed]

15. Müller, C.; Leithner, K.; Hauptstein, S.; Hintzen, F.; Salvenmoser, W.; Bernkop-Schnürch, A. Preparation and characterization of mucus-penetrating papain/poly(acrylic acid) nanoparticles for oral drug delivery applications. J. Nanoparticle Res. 2013, 15. [CrossRef]

16. Muss, C.; Mosgoeller, W.; Endler, T. Papaya preparation (Caricol $\left.{ }^{\circledR}\right)$ in digestive disorders. Neuro Endocrinol. Lett. 2013, 34, 38-46.

17. Osato, J.A.; Santiago, L.A.; Remo, G.M.; Cuadra, M.S.; Mori, A. Antimicrobial and antioxidant activities of unripe papaya. Life Sci. 1993, 53, 1383-1389. [CrossRef]

18. Cho, C.H.; Han, P.W. Papain reduces gastric acid secretion induced by histamine and other secretagogues in anesthetized rats. Proc. Natl. Sci. Counc. Repub. China B 1984, 8, 177-181. 
19. Miller, S.S.; Fulcher, R.G. Microstructure and chemistry of the oat kernel. In Oats: Chemistry and Technology; American Association of Cereal Chemists, Inc. (AACC): Saint Paul, MN, USA, 2011; pp. 77-94.

20. Yiu, S.H. Effects of processing and cooking on the structural and microchemical composition of oats. Food Struct. 1986, 5, 219-225.

21. Hartunian Sowa, S.; White, P. Characterization of starch isolated from oat groats with different amounts of lipid. Cereal Chem. 1992, 69, 521-527.

22. Choi, I.; Han, O.K.; Chun, J.; Kang, C.S.; Kim, K.H.; Kim, Y.K.; Cheong, Y.K.; Park, T.I.; Choi, J.S.; Kim, K.J. Hydration and pasting properties of oat (Avena sativa) flour. Prev. Nutr. Food Sci. 2012, 17, 87-91. [CrossRef]

23. Liu, Y.; Bailey, T.B.; White, P.J. Individual and Interactional Effects of $\beta$-Glucan, Starch, and Protein on Pasting Properties of Oat Flours. J. Agric. Food Chem. 2010, 58, 9198-9203. [CrossRef] [PubMed]

24. Niu, Q.; Pu, Y.; Li, X.; Ma, Z.; Hu, X. Solvent retention capacities of oat flour. Int. J. Mol. Sci. 2017, 18, 590. [CrossRef] [PubMed]

25. Smart, J.D. The basics and underlying mechanisms of mucoadhesion. Adv. Drug. Deliv. Rev. 2005, 57, 1556-1568. [CrossRef] [PubMed]

26. Gu, J.M.; Robinson, J.R.; Leung, S.H.S. Binding of acrylic polymers to mucin/epithelial surfaces: Structure-property relationships. Crit. Rev. Ther. Drug Carrier Syst. 1988, 5, 21-67. [PubMed]

27. Mortazavi, S.A.; Smart, J.D. An investigation into the role of water movement and mucus gel dehydration in mucoadhesion. J. Control. Release 1993, 25, 197-203. [CrossRef]

28. Cook, S.L.; Bull, S.P.; Methven, L.; Parker, J.K.; Khutoryanskiy, V.V. Mucoadhesion: A food perspective. Food Hydrocoll. 2017, 72, 281-296. [CrossRef]

29. Jabbari, E.; Wisniewski, N.; Peppas, N.A. Evidence of mucoadhesion by chain interpenetration at a poly (acrylic acid)/mucin interface using ATR-FTIR spectroscopy. J. Control. Release 1993, 26, 99-108. [CrossRef]

30. Mikos, A.G.; Peppas, N.A. Measurement of the surface tension of mucin solutions. Int. J. Pharm. 1989, 53, 1-5. [CrossRef]

31. Bernkop-Schnürch, A. Thiomers: A new generation of mucoadhesive polymers. Adv. Drug Deliv. Rev. 2005, 57, 1569-1582. [CrossRef]

32. Derjaguin, B.V.; Aleinikova, I.N.; Toporov, Y.P. On the role of electrostatic forces in the adhesion of polymer particles to solid surfaces. Prog. Surf. Sci. 1994, 45, 119-123. [CrossRef]

33. Derjaguin, B.V.; Toporov, Y.P.; Muller, V.M.; Aleinikova, I.N. On the relationship between the electrostatic and the molecular component of the adhesion of elastic particles to a solid surface. J. Colloid. Interface Sci. 1977, 58, 528-533. [CrossRef]

34. Huang, Y.; Leobandung, W.; Foss, A.; Peppas, N.A. Molecular aspects of muco- and bioadhesion: Tethered structures and site-specific surfaces. J. Control. Release 2000, 65, 63-71. [CrossRef]

35. Park, H.; Robinson, J.R. Mechanisms of Mucoadhesion of Poly/acrylic Acid) Hydrogels. Pharm. Res. 1987, 6 , 457-464. [CrossRef] [PubMed]

36. Pund, S.; Joshi, A.; Vasu, K.; Nivsarkar, M.; Shishoo, C. Gastroretentive delivery of rifampicin: In vitro mucoadhesion and in vivo gamma scintigraphy. Int. J. Pharm. 2011, 411, 106-112. [CrossRef]

37. Chen, H.; Rogalski, M.M.; Anker, J.N. Advances in functional X-ray imaging techniques and contrastagents. Phys. Chem. Chem. Phys. 2013, 14, 13469-13486. [CrossRef]

38. Kita, M.; Negi, A.; Kawano, S.; Honda, Y.; Maegawa, S. Measurement of retinal adhesive force in the in vivo rabbit eye. Investig. Ophthalmol. Vis. Sci. 1990, 31, 624-628.

39. Davidovich-Pinhas, M.; Bianco-Peled, H. Methods to Study Mucoadhesive Dosage Forms. Mucoadhesive Mater. Drug Deliv. Syst. 2014, 9781119941, 175-196. [CrossRef]

40. Andrews, G.P.; Laverty, T.P.; Jones, D.S. Mucoadhesive polymeric platforms for controlled drug delivery. Eur. J. Pharm. Biopharm. 2009, 71, 505-518. [CrossRef]

41. Mansuri, S.; Kesharwani, P.; Jain, K.; Tekade, R.K.; Jain, N.K. Mucoadhesion: A promising approach in drug delivery system. React. Funct. Polym. 2016, 100, 151-172. [CrossRef]

42. Lubes, G.; Goodarzi, M. GC-MS based metabolomics used for the identification of cancer volatile organic compounds as biomarkers. J. Pharm. Biomed. Anal. 2017. [CrossRef]

43. Esposito, P.; Colombo, I.; Lovrecich, M. Investigation of surface properties of some polymers by a thermodynamic and mechanical approach: Possibility of predicting mucoadhesion and biocompatibility. Biomaterials 1994, 15, 177-182. [CrossRef] 
44. Belgamwar, V.; Shah, V.; Surana, S.J. Formulation and evaluation of oral mucoadhesive multiparticulate system containing metoprolol tartarate: An in vitro-ex vivo characterization. Curr. Drug Deliv. 2009, 6, 113-121. [CrossRef] [PubMed]

45. Gradauer, K.; Vonach, C.; Leitinger, G.; Kolb, D.; Fröhlich, E.; Roblegg, E.; Bernkop-Schnürch, A.; Prassl, R. Chemical coupling of thiolated chitosan to preformed liposomes improves mucoadhesive properties. Int. J. Nanomed. 2012, 7, 2523-2534. [CrossRef]

46. Rossi, S.; Vigani, B.; Bonferoni, M.C.; Sandri, G.; Caramella, C.; Ferrari, F. Rheological analysis and mucoadhesion: A 30 year-old and still active combination. J. Pharm. Biomed. Anal. 2018, 156, 232-238. [CrossRef]

47. Tambe, A.; Mokashi, P.; Pandita, N. Ex-vivo intestinal absorption study of boswellic acid, cyclodextrin complexes and poloxamer solid dispersions using everted gut sac technique. J. Pharm. Biomed. Anal. 2019, 167, 66-73. [CrossRef]

48. Tetyczka, C.; Griesbacher, M.; Absenger-Novak, M.; Fröhlich, E.; Roblegg, E. Development of nanostructured lipid carriers for intraoral delivery of Domperidone. Int. J. Pharm. 2017, 526, 188-198. [CrossRef]

49. United States Pharmacopoeia; United States Pharmacopeial Convention, Inc.: Rockville, MD, USA, 1990.

50. Van der Reijden, W.A.; van der Kwaak, H.; Vissink, A.; Veerman, E.C.; Amerongen, A.V.N. Treatment of xerostomia with polymer-based saliva substitutes in patients with Sjogren's syndrome. Arthritis Rheum. 1996, 39, 57-63. [CrossRef]

51. Collado-González, M.; González Espinosa, Y.; Goycoolea, F.M. Interaction Between Chitosan and Mucin: Fundamentals and Applications. Biomimetics 2019, 4, 32. [CrossRef]

52. Rossi, S.; Bonferoni, M.C.; Ferrari, F.; Bertoni, M.; Caramella, C. Characterization of mucin interaction with three viscosity grades of sodium carboxymethylcellulose. Comparison between rheological and tensile testing. Eur. J. Pharm. Sci. 1996, 4, 189-196. [CrossRef]

53. Rossi, S.; Bonferoni, M.C.; Lippoli, G.; Bertoni, M.; Ferrari, F.; Caramella, C.; Conte, U. Influence of mucin type on polymer-mucin rheological interactions. Biomaterials 1995, 16, 1073-1079. [CrossRef]

54. Berry, J.D.; Neeson, M.J.; Dagastine, R.R.; Chan, D.Y.; Tabor, R.F. Measurement of surface and interfacial tension using pendant drop tensiometry. J. Colloid Interface Sci. 2015, 454, 226-237. [CrossRef] [PubMed]

55. Yildiz, B.; Bashiry, V. Shape analysis of a sessile drop on a flat solid surface. J. Adhes. 2019, 95, 929-942. [CrossRef]

56. Lai, S.K.; Wang, Y.Y.; Wirtz, D.; Hanes, J. Micro- and macrorheology of mucus. Adv. Drug Deliv. Rev. 2009, 61, 86-100. [CrossRef] [PubMed]

57. Madsen, F.; Eberth, K.; Smart, J.D. A rheological examination of the mucoadhesive/mucus interaction: The effect of mucoadhesive type and concentration. J. Control. Release 1998, 50, 167-178. [CrossRef]

58. Sriamornsak, P.; Wattanakorn, N.; Nunthanid, J.; Puttipipatkhachorn, S. Mucoadhesion of pectin as evidence by wettability and chain interpenetration. Carbohydr. Polym. 2008, 74, 458-467. [CrossRef]

59. Starley, I.F.; Mohammed, P.; Schneider, G.; Bickler, S.W. The treatment of paediatric burns using topical papaya. Burns 1999, 25, 636-639. [CrossRef]

60. Wang, M.; Wei, L.; Zhu, P.; Du, X.; Zhou, Y. Effect of inulin on rheological properties and in vitro digestion of potato starch paste. J. Chin. Cereals Oils Assoc. 2016, 31, 47-51.

61. Westerlund, E.; Åman, P.; Andersson, R.; Andersson, R.E.; Rahman, S.M.M. Chemical characterization of water-soluble pectin in papaya fruit. Carbohydr. Polym. 1991, 15, 67-78. [CrossRef]

62. Wu, P.; Dhital, S.; Williams, B.A.; Chen, X.D.; Gidley, M.J. Rheological and microstructural properties of porcine gastric digesta and diets containing pectin or mango powder. Carbohydr. Polym. 2016, 148, $216-226$. [CrossRef]

(C) 2020 by the authors. Licensee MDPI, Basel, Switzerland. This article is an open access article distributed under the terms and conditions of the Creative Commons Attribution (CC BY) license (http://creativecommons.org/licenses/by/4.0/). 